\title{
Bioprospecção de Microorganismos de Interesse Biotecnológico Isolados em Ecossistema de Manguezal
}

\author{
Bioprospecting of Microorganisms with Biotechnological Interest Isolated in \\ Mangrove Ecosystem
}

Léo Ruben Lopes Dias ${ }^{1}$; Diana Karla Lourenço Bastos ${ }^{1}$; Neuriane Silva Lima ${ }^{2}$; Maria Raimunda Chagas Silva ${ }^{3}$; Rita de Cássia Mendonça de Miranda ${ }^{3}$.

\begin{abstract}
Resumo: O manguezal é um ecossistema rico, porém muito limitante para o crescimento microbiano, por ser um ecossistema de transição o mesmo limita a diversidade microbiana, de fauna e flora. Nesse contexto, os microorganismos que estão presentes nesse habitat possuem habilidades de sobrevivência interessantes no contexto biotecnológico, sendo potenciais produtores de enzimas de interesse industrial. Após feita a coleta, foram realizadas análises físico-químicas do solo com o intuito de se conhecer as propriedades de granulometria, matéria orgânica, umidade e pH. Após o isolamento e identificação dos microorganismos do solo da área de manguezal, foi encontrada uma variedade de bactérias e fungos, totalizando dezesseis bactérias equivalentes a $68,75 \%$ dos microorganismos totais entre elas um actinomiceto e cinco fungos equivalentes a $31,25 \%$ das amostras. Estes microorganismos passaram por uma seleção de crescimento em meios de culturas diversificados e foram identificados através de sua macromorfologia e microscopia óptica por meio de coloração de gram.
\end{abstract}

Palavras-chave: Bioprospecção, Isolamento, Microorganismos.

\begin{abstract}
The mangrove is a rich ecossystem, but very limiting for the microbial growth, being a transition ecosystem the same limits the microbial diversity, of fauna and flora. In this context, the microorganisms that are present in this habitat have interesting survival skills in the biotechnological context, being potential producers of enzymes of industrial interest. After the collection, physicalchemical analyzes of the soil were carried out with the purpose of knowing the properties of granulometry, organic matter, humidity and $\mathrm{pH}$. After isolating and identification soil microorganisms from the mangrove area, a variety of bacteria and fungi were found, totaling sixteen bacteria equivalente to $68,75 \%$ of the total microorganisms including a actinomycete and five fungi equivalente to $31,25 \%$ of the samples. These microorganisms underwent a selection growth in diverse culture media and were identified through their macromorphology and optical microscopy by gram staining. Physical and chemical analysis of the soil was carried out in order to know its properties.
\end{abstract}

Keywords: Bioprospecting, Isolation, Microorganisms.

1. Graduando em Biomedicina; Universidade Ceuma

2. Graduanda em Engenharia Ambiental, Universidade Ceuma

3. Docentes Doutoras do Mestrado em Meio Ambiente, Universidade Ceuma 


\section{Introdução}

A natureza tem sido um recurso excepcional de novos compostos biologicamente ativos, visto que uma incrível diversidade química é encontrada no grande número de espécies de plantas, animais, organismos marinhos e microorganismos $^{1} \quad$ garantindo a biodiversidade que, por sua vez, está intrinsecamente ligada ao local em que estes seres se encontram. Um dos locais destes ecossistemas é o mangue que compreende uma área de transição entre o ambiente terrestre e marinho, característico de regiões tropicais e subtropicais.

As espécies encontradas no manguezal têm um grande potencial biotecnológico e são fontes para novos compostos que podem ter diversas aplicações na indústria de medicamentos, uma vez que alguns dos microorganismos encontrados apresentam atividade antimicrobiana, antioxidante e outros princípios ativos com propriedades farmacológicas ${ }^{2}$.

A notável diversidade bioquímica dos microorganismos tem sido explorada pelas indústrias, isolando cepas do ambiente natural capazes de produzir produtos de valor comercial ${ }^{3}$, como por exemplo metabólitos secundários com diversas aplicações, já que estes apresentam uma importante fonte de compostos bioativos.

Visando a necessidade de busca por compostos bioativos e microorganismos clínicos que possam combater fitopatógenos e se apresentar como antimicrobianos, esta pesquisa teve como objetivo realizar a bioprospecção de microorganismos isolados em ecossistema do mangue que possuíssem interesse biotecnológico como atividade antimicrobiana, frente a microorganismos clínicos e
agrícolas.

\section{Material e método}

Coleta: Com a finalidade de selecionar um ou mais microorganismos de interesse biotecnológico foi realizada uma coleta de solo de manguezal. As amostras foram acondicionadas em sacos plásticos e encaminhadas para - Laboratório de Microbiologia Ambiental na Universidade CEUMA. No laboratório, os solos foram misturados e alíquotas foram retiradas para avaliação microbiológica. Posteriormente os microorganismos isolados foram armazenados a $4{ }^{\circ} \mathrm{C}$.

Caracterização Físico-Química do Solo: Com o objetivo de se conhecer as propriedades químicas e físicas do solo, foram realizadas análises físicoquímicas do mesmo, coletados em 5 pontos denominados "P" e numerados em uma sequência crescente de um a cinco, onde foram determinados os teores de matéria orgânica, $\mathrm{pH}$, umidade e granulometria com base na metodologia do Standard Method.

Isolamento: $\mathrm{O}$ isolamento dos microorganismos foi realizado segundo a técnica de Clark (1965), no qual $25 \mathrm{~g}$ de solo do ambiente possivelmente contaminado e possivelmente não contaminado foram adicionados a 225 $\mathrm{mL}$ de água destilada esterilizada. Posteriormente foram feitas diluições seriadas de 1:10 até a diluição de 10 6. Um volume de $1 \mathrm{~mL}$ foi inoculado em meios de cultura seletivos diferenciados adicionados a antibióticos para evitar a proliferação de contaminantes. O experimento foi realizado em triplicata. As placas foram incubadas a $30 \stackrel{\circ}{\circ}$ em condições de laboratório por no máximo 10 dias. Posteriormente foi 
realizada uma triagem em cada placa, onde foram observadas as características macromorfológicas das colônias para posterior purificação e repicagem para tubo de ensaio. Estas colônias foram armazenadas em geladeira a $4 \quad \stackrel{\circ}{ } \mathrm{C}$ até a completa identificação.

Identificação: A identificação dos microorganismos selecionados foi realizada por metodologia clássica onde as bactérias foram divididas em dois grandes grupos pela coloração diferencial da parede celular em Bactérias Gram positivas e Gram negativas, além de testes bioquímicos de utilização de diferentes carboidratos, motilidade, produção de sulfeto $e$ indol. Os fungos filamentosos foram isolados a partir de solo contaminado e não contaminado e identificados através da técnica de microcultivo onde foram observadas a produção de arrumação dos esporos.

\section{Resultados}

$\mathrm{O}$ isolamento de microorganismos do ambiente tem interessado o ramo da biotecnologia atualmente, uma vez que a notável diversidade química dos microorganismos tem sido explorada pelas indústrias, que isolam cepas do ambiente natural capazes de produzir produtos de valor comercial com interesses biotecnológicos diversos ${ }^{3}$.

A fim de caracterizar o solo do mangue na região pesquisada em questão fornecendo elementos para melhor conhecimento desse ecossistema, foram coletadas amostras em 5 pontos da área cujas coordenadas de localização se encontram na tabela 1, as mesmas foram submetidas a análises físicas e químicas de granulometria, matéria orgânica, umidade e pH onde os valores encontrados foram listados na tabela 2.

Tabela 1 - Coordenadas dos pontos de solo coletados.

\begin{tabular}{c|c}
\hline Pontos & Coordenadas \\
\hline P1 & $\mathrm{SO} 2^{\circ}=27^{\prime} 12.0^{\prime \prime}$ \\
& $\mathrm{W}=044^{\circ} 09^{\prime} 34.0^{\prime \prime}$ \\
\hline P2 & $\mathrm{SO} 2^{\circ}=27^{\prime} 10.0^{\prime \prime}$ \\
& $\mathrm{W}=044^{\circ} 09^{\prime} 36.5^{\prime \prime}$ \\
\hline P3 & $\mathrm{SO}=2^{\circ} 27^{\prime} 08.5^{\prime \prime}$ \\
& $\mathrm{WO}=44^{\circ} 09^{\prime} 36.5^{\prime \prime}$ \\
\hline P4 & $\mathrm{SO}=2^{\circ} 27^{\prime} 07,7^{\prime \prime}$ \\
& $\mathrm{WO}=44^{\circ} 09^{\prime} 36.1^{\prime \prime}$ \\
\hline P5 & $\mathrm{SO}=2^{\circ} 27^{\prime} 07.8^{\prime \prime}$ \\
& $W O=44^{\circ} 09^{\prime} 35.4^{\prime \prime}$ \\
\hline
\end{tabular}

Tabela 2 - Características Físico-Químicas do Solo.

\begin{tabular}{c|c|c|c|c|c|c}
\hline Pontos & Argila & Silte & $\begin{array}{c}\text { Areia } \\
\text { Fina }\end{array}$ & M. Orgânica & Umidade & pH \\
\hline P1 & $8,32 \%$ & $21,08 \%$ & $69,88 \%$ & $24,62 \%$ & $26,6 \%$ & 7,52 \\
\hline P2 & $11,72 \%$ & $10,74 \%$ & $77,54 \%$ & $11,25 \%$ & $2,10 \%$ & 7,09 \\
\hline P3 & $8,46 \%$ & $16,78 \%$ & $74,76 \%$ & $30,01 \%$ & $35,92 \%$ & 7,92 \\
\hline P4 & $10,14 \%$ & $32,09 \%$ & $78,61 \%$ & $61,23 \%$ & $5,33 \%$ & 8,02 \\
\hline P5 & $5,14 \%$ & $19,49 \%$ & $62,77 \%$ & $22,52 \%$ & $38,13 \%$ & 8,27 \\
\hline
\end{tabular}


Foi realizado o isolamento de solo contaminado e não contaminado na região do Mangue Seco no município da Raposa onde foram obtidos 16 bactérias e 5 fungos isolados, como ilustrado na figura 1 . Durante esse período, um processo de purificação e seleção foi desenvolvido para a obtenção e crescimento dos microorganismos encontrados, onde os critérios foram as características macro e microscópicas. As bactérias isoladas receberam a inicial "B", seguidas de uma sequência numérica crescente de 1 a 16 ao passo que os fungos isolados receberam a inicial " $F$ ", seguidos de uma sequência numérica crescente de 1 a 5 .

Figura 1 - Percentual de Microorganismos Isolados.

Após 0 isolamento dos microorganismos e seleção de seu crescimento através do cultivo em meios seletivos para bactérias e para fungos, foi realizada a identificação das bactérias através da coloração de
Gram, onde estas foram classificadas em Gram negativas ou Gram positivas de acordo com a coloração tintorial da parede celular. Observou-se também sua estrutura microscópica, como mostrado na figura 2.

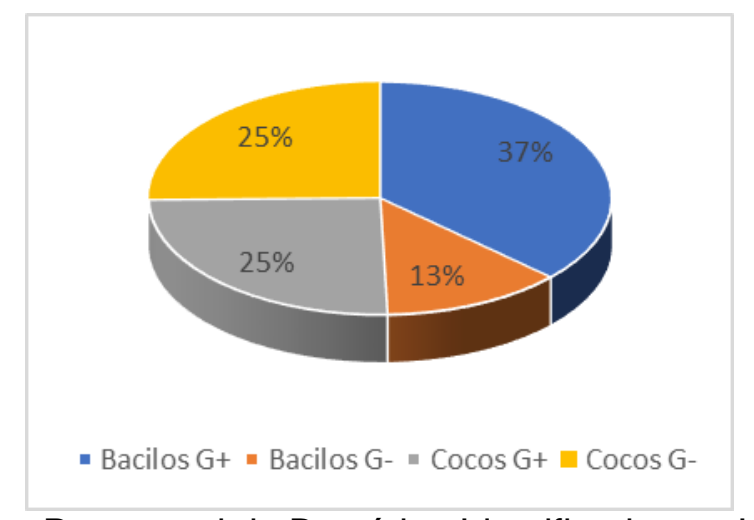

Figura 2 - Percentual de Bactérias Identificadas no Isolamento

Os fungos filamentosos foram identificados quanto ao gênero pelas características microscópicas das colônias, após o preparo de cultivos em lâminas como mostra a figura 3 . Nesta figura podemos observar a estrutura 3A destacada com a seta indicando a hifa hialina, com esporângio na extremidade caracterizando o saco que determina o gênero Aspergillus. Podemos observar também a estrutura 3B onde 
a seta aponta para uma característica dos esporos do fungo classificado como Aspergillus destacando seus esporângios na extremidade indicando o saco que nos mostra o gênero descrito acima. Na estrutura $3 \mathrm{C}$ a seta indica uma morfologia que se trata de esporos de resistência na hifa do fungo classificado como Trichoderma.

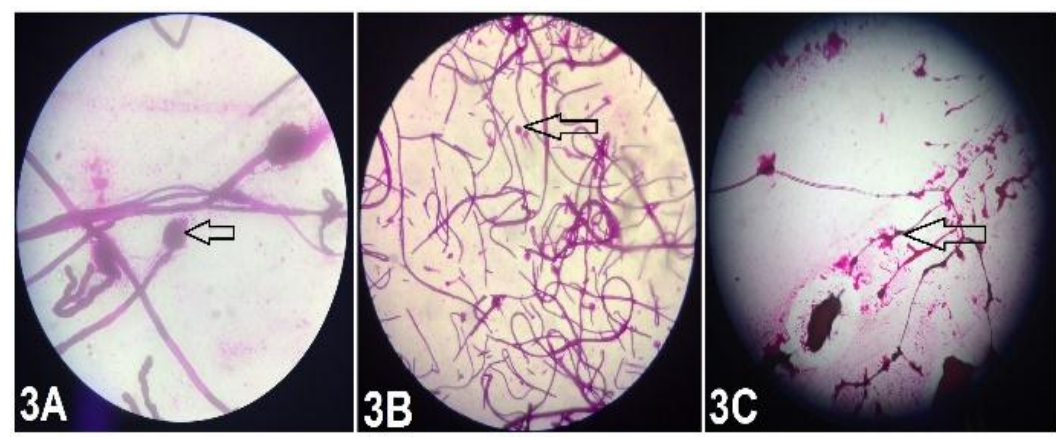

Figura 3 - Observação microscópica da morfologia dos fungos em lente objetiva de 40x.

As características macro morfológicas dos fungos foram levadas em consideração e observadas nas placas de cultivos em meio ágar saboraund para melhor identificação, ilustrados na tabela 4 . Podemos observar na estrutura 4A do fungo Aspergillus sp. uma colônia esponjosa de bordas irregulares, abaulamento em vários pontos com presença de aspecto irregular esverdeado e acinzentado. $\mathrm{Na}$ estrutura 4B do fungo Aspergillus sp. fica evidenciada a presença de colônias algodonosas e regulares, apresentando bordas regulares com predominância em toda a placa e micélio aéreo com coloração amarelada. A estrutura $4 \mathrm{C}$ do fungo Trichoderma sp. nos mostra uma colônia de fungos amarelada de aspecto leitoso e ondulações esbranquiçadas apresentando bordas irregulares. Fica notório na estrutura 4D o aparecimento de colônias fúngicas predominantemente leitosas em cor amarelada, bordas irregulares com pequenas ondulações e depressões evidentes.

Após a observação micro e macroscópica dos fungos isolados no ecossistema de manguezal, foi concluído que dos 5 fungos encontrados onde apenas 4 foram identificados, apresentaram características que os classificaram em 3 gêneros distintos como mostrados na tabela 3. Contudo, embora tenha se obtido uma quantificação expressiva de fungos no meio Sabouraud, este mesmo resultado não foi refletido quanto a diversidade desses organismos. 


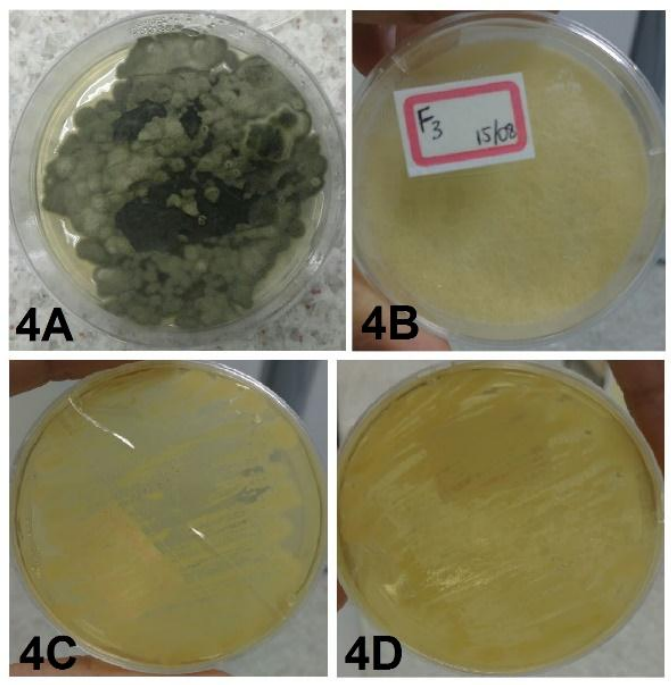

Figura 4 - Observação macro morfológica dos fungos cultivados em placas de Petri contendo meio Ágar Sabouraud.

Tabela 3 - Identificação dos Fungos isolados quanto ao gênero.

\begin{tabular}{c|c}
\hline Códigos & Identificação Fúngica \\
\hline F1 & Não identificado. \\
\hline F2 & Aspergillus sp. \\
\hline F3 & Aspergillus sp. \\
\hline F4 & Trichoderma sp. \\
\hline F5 & Streptomyces sp. \\
\hline
\end{tabular}

\section{Discussão}

As principais características físico-químicas dos solos nos pontos coletados foram listadas na Tabela 3 onde podemos concluir que a classificação dos solos nos pontos $\mathrm{P} 1$, P3, P4 e P5 foram de areia fina à média Siltosa à Argilosa e somente o ponto P2 apresentou a característica de areia fina à média argilosa à Siltosa. O Silte é responsável pela ocorrência da textura média nos pontos e Radambrasil ${ }^{4}$ se refere aos solos do mangue como sendo bem argilosos, e também dos dados de
Odum $^{5}$ e Cintron ${ }^{6}$, quando comentam que o solo de mangue é formado por extensos depósitos de argila e lodo.

Dentre as bactérias isoladas no solo de manguezal um grupo pertinente pode ser descrito pela ordem Actinomycetales que se manteve constante junto ao aparecimento de outras bactérias que se apresentaram em arranjo de cocos gram positivos e negativos, e bacilos gram positivos e negativos. Isto evidencia a estabilidade de Actinomicetos nesse ecossistema que independe de condições climáticas específicas. Este grupo de bactérias é 
conhecido como colonizador de solos, onde parece responder pouco a alterações ambientais de acordo com as afirmações de Tiago et al., ${ }^{7}$ e Liu et al. ${ }^{8}$.

Estudando a ecologia de microfungos em solo de manguezal, Lee e Baker ${ }^{9}$ isolaram mais de 50 espécies, dentre elas um número considerável de Aspergillus e Trichoderma. O mesmo foi observado nos estudos realizados em solo de manguezal por Segrupta e Chaudhuri ${ }^{10}$, isolando muitos gêneros dentre eles Aspergillus. Esses dois gêneros de fungos mencionados tiveram um aparecimento considerável no isolamento realizado na pesquisa.

\section{Referências}

1. Choffnes, E. et al., Antibiotic Resistance: Implications for Global Health and Novel Intervention Strategies: Workshop Antibiotic Resistance... Anais. Washington: National Academy of Science, 2010.

2. Strobel, G.; Daisy, B. Bioprospecting for Microbial Endophytes and Their Natural Products. Microbiology and Molecular Biology Reviews, v.67, n. 4, p. 491-502, 2003.

3. Davies, J. (2011). How to discover new antibiotics: harvesting the pravome. Current Opinion in Chemical Biology, $15,5-10$.
4. Radambrasil. (1983) Ministério das Minas e Energia. Levantamento dos Recursos Naturais. Folhas SF 23/24, Rio de Janeiro/Vitória. Rio de Janeiro, v. $32.780 p$

5. Odum, E.P. (1972) Ecologia. Trad. C. G. Ottenwaelder, 3.ed. México, Nueva Editorial Interamericana. $639 \mathrm{p}$.

6. Cintron, g.; Schaeffer-Novelli, Y. (1983) Factores abioticos. In: Introducción a la ecologia del manglar. UNESCOROSTLAC. p.19-29.

7. Tiago I.; Chung A. P.: Verissimo A. Bacterial Diversity in a Nonsaline Alkaline Enviroment: Heterotrophic Aerobic Populations. Apllied and environmental microbiology, $v$ 12, $p$. 7378-7387, 2004.

8. Liu, J.; Nakayama, T., Hemmi H., Asano, y., Tsuruoka, N., Shimomura, K., Nishijima, M.; Nishimo, T. Microbacterium natoriense sp. Nov., a novel D-aminoacylase-producing bacterium isolated from soil in Natori, Japan. International Journal of systematic and evolutionary microbiology, v 55, p. 661-665, 2005.

9. Lee, B. K. H; Baker, G. E. An ecological study of the soil microfungi in a Hawaiian Mangrove swamp. Pacific Science, v. 26, p. 1-10, 1972.

10. Sengupta, A.; Chaudhuri, S. Ecology of microfungi in mangroves sediments at the Ganges river estuary in Índia. Indian Forester, p. 807-812, 1995. 